\title{
Impact of Social Media Application Qualities on Using Them for Daily News
}

\author{
Davod Farhadi ${ }^{1}$, Ali Maroosi ${ }^{2}$ \\ ${ }^{1}$ Department of Computer Engineering, Islamic Azad University, Ferdows Branch, Ferdows, Iran \\ ${ }^{2}$ Department of Computer Engineering, University of Torbat Heydarieh, Torbat Heydarieh, Iran \\ Corresponding author: Ali Maroosi (ali.maroosi@torbath.ac.ir)
}

\begin{abstract}
A model is introduced to investigate the effect of social media application qualities on the using of these applications for daily news. A standard questionnaire was designed and distributed among randomly selected social media users in the city of Neyshabur in Iran. The content of the questionnaire was validated by experts and its reliability verified using Cronbach's alpha. Random sampling was used identify participants. The SmartPLS software was used to investigate the research findings. Structural equation modelling is used for data analysis. The results show that the factors of system quality, information quality, service quality and personalization of applications affect their perceived usefulness. System quality and service quality affect the perceived ease of use of applications. However, information quality does not affect perceived ease of use. Also, the results show that perceived usefulness has a greater effect (with a path coefficient of $45 \%$ ) on the attitude in respect of perceived ease of use (path coefficient of $26 \%$ ). Personalization has the most positive impact on perceived usefulness and service quality has a great impact on perceived ease of use. Facilitating conditions have a positive impact on the use of social media and their use for news. Furthermore, the results show that the factors that affect the use of applications in Telegram are better than those in Viber. These findings justify why Iranian people migrate from Viber to Telegram as their social media application.
\end{abstract}

\section{Keywords}

Application software; Information technology; Social media; Information quality. 


\section{Introduction}

Recently, all aspects of human life, including economy, society, culture and politics, have been influenced by the use of information and communication technology, especially expanded social media. Virtual social media are currently the sturdiest online media in the world. These networks are widely welcomed by users due to their plurality, content diversity and different internet and software functionalities. Social media are actually a private virtual space where by storing their data, people are able to share texts and images and communicate with others (Schillinger and Schindelhauer, 2020; Chaeikar et al., 2021). In other words, the virtual space provides an opportunity for establishing new communities for users. Different factors contributing to the use of social media should be evaluated to be able to provide better services in the social media. The factors contributing to a useful program include system quality, data quality, service quality and personalization. System quality includes some favourable features such as ease of use, flexibility and reliability (Li and Shang, 2020). By providing simple and understandable information, modern systems of electronic interactions and communications enable information systems to effectively improve high-quality performance for users and such information will help the organization enhance its business processes, raise its performance and present a favourable capability to users in the upcoming interactions (Al-Mamary et al., 2014).

Users' performance is influenced by information quality, directly or indirectly, through understanding its benefits and the ease of use in organizations (Ullah et al., 2020). Perceived quality of the services is actually recognized, judged or realized by the user regarding the merit of services, and quality of services reflects the range of user feedback about the presented services. Service quality is divided into two general groups: technical quality, which refers to the output of services, and performance quality, which refers to the process of transferring quality (Aliman and Mohamad, 2016). Many scholars believe that quality of services has an in-depth impact on user satisfaction and leads to their loyalty to the organization (Duy and Hoang, 2017). Although many factors contribute to consumer attitudes and intentions, quality of services is the most important factor (Pang et al., 2020). Despite many studies conducted on social media, there is still no certain study on the use of social media and their applications for news. Thus, this study investigates the impact of application qualities on the use of social media for news.

\section{Literature review}

Numerous studies have been carried out on the impact of social media on society. Kang et al. (2014) stated that when people have more interaction on social pages related to a certain firm, the possibility of visiting those pages is higher and their trust and commitment increases. Nuryanti et al. (2021) show that system quality and information quality have a significant positive effect on information system user satisfaction. There is also a significant relationship between system quality and information quality, such that system quality and information quality are considered a major factor in perceiving electronic interactions and improving organizational performance (Al-Mamary et al., 2014). Studies have shown the impact of system quality on users' performance and also found a direct and strong relationship between these two variables (Nurbani and Meiyanti, 2019). Others argue that service quality is a criterion for judgment on products or services (Hanks et al., 2017; Meesala and Paul, 2018). There is also strong support for the relationship between system quality and user satisfaction (Vijai, 2018). Thus, system quality should be considered in designing a software application (Grange and Barki, 2020).

The quality of a system used by individuals has positive impacts on the individuals and organizational performance (Chan and Lau, 2018). Information quality is another factor that affects user satisfaction; research by Kang and Namkung (2019) shows that information quality is related to purchase frequency from online applications. Information quality is an important predictor of online consumers' trust, satisfaction with the goods presented by the electronic retailer, and purchase intention (Yuan et al., 2018). According to the technology acceptance model, the perceived usefulness and ease of use are two major 
factors of system adoption and use (Mensah, 2020). The technology acceptance model (TAM) is used in predicting users' intention to adopt internet banking (Rahi et al., 2018). The TAM is a powerful model for predicting and describing electronic government. The TAM is also a powerful model that hypothesizes direct and indirect mechanisms leading to technology use by teachers (Scherer et al., 2019). Perceived ease of use, perceived usefulness, and attitude and intention to use are considered the basic variables of the TAM. In a study by Hsu et al. (2014), the perceived ease of use has a positive effect on the attitude of users and perceived usefulness. Hussein et al. (2021) and Islami et al. (2021) show that perceived usefulness has a positive effect on users' attitude. Moreover, facilitating conditions have a positive impact on the intention to use (König and Grippenkoven, 2020). Almaiah et al. (2016) investigated factors that affect use of mobile phones for training courses.

Viber was one of the first popular social messengers in Iran (Khiabany, 2018). However, it was gradually replaced by Telegram (Yalcintas and Alizadeh, 2020). About 40 million people, i.e., about 50 percent of Iran's population, use Telegram (Shayegan and Valizadeh, 2020; Hashemi and Zare Chahooki, 2019; Akbari and Gabdulhakov, 2019). That is why we investigated and compared the quality of the Telegram social media app that has replaced the Viber app to show how application characteristics affect using social media applications.

Different studies have been made on using social media messengers in Iran. The work by Narmenji et al. (2020) shows that Telegram is used more than Instagram and WhatsApp for sharing information among students. Gilavand et al. (2017) indicate that Telegram is used the most for learning and education (50\%), followed by WhatsApp (26\%), Viber (7\%), Facebook (5\%), Instagram (2\%) and others (11\%). Sarafraz et al. (2019) demonstrate that the use of Telegram, WhatsApp and Instagram has a positive effect on anxiety and depression on students from Shiraz, Iran. The method proposed by Karimpour et al. (2021) recommends groups based on users' interests, using their membership and analysing their membership records. Faramarzi et al. (2019) discussed that features of Telegram, including access to channels and groups, supporting files with various extensions and size, compatibility with different operating systems and devices, make it useful for distance language learning. Shayegan and Valizadeh (2020) proposed a recommender system based on the analysis of personality traits in the Telegram social network. They automatically identified users' personalities according to their behaviour on Telegram. Then, they provided a recommender system based on the personality traits. Mehdipour et al. (2021) analysed health information in social media during the COVID pandemic in Iran and showed that in the first weeks of the COVID pandemic, people may not had taken its risks seriously.

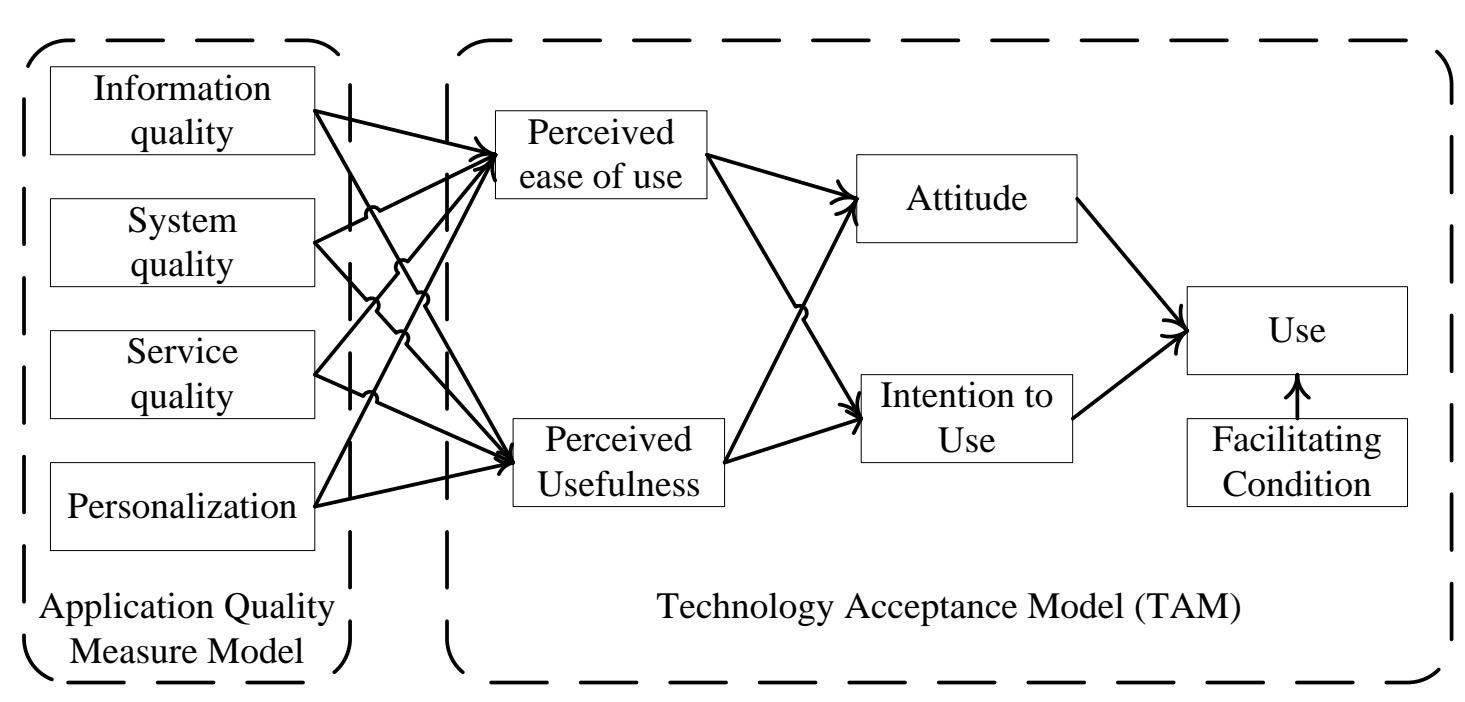

Figure 1. Proposed conceptual model for social media application use for news. 
In this study, we propose a research model achieved by combining two models: one that examines application design quality, called the information success model (Halawi et al., 2008; Vijai, 2018; Chen et al., 2017) and the TAM (Shaikh et al., 2015; Rahi et al., 2018). This model evaluates the impact of quality factors of applications on the use of social media for news (see Figure 1).

\section{Research hypotheses}

Given the analysis of theoretical principles and studies conducted, the fundamental and ancillary hypotheses of the study are formulated as follows:

H1: The system quality of a social media application affects its perceived usefulness.

H2: The information quality of a social media application affects its perceived usefulness.

H3: The service quality of a social media application affects its perceived usefulness.

H4: The personalization of a social media application affects its perceived usefulness.

H5: The system quality of a social media application affects the perceived ease of its use.

H6: The information quality of a social media application affects the perceived ease of its use.

H7: The service quality of a social media application affects the perceived ease of its use.

H8: The personalization of a social media application affects the perceived ease of its use.

H9: The perceived ease of using a social media application affects its perceived usefulness.

H10: The perceived usefulness of using a social media application affects the attitude to using it.

H11: The perceived ease of using a social media application affects the attitude to using it.

H12: The attitude to using a social media application affects the use of social media for news.

H13: The attitude to using a social media application affects the intention to use it.

H14: The facilitating conditions affect the use of social media for news.

H15: The facilitating conditions affect the use of social media.

H16: The intention to use a social media for news affects using it for news.

H17: The intention to use a social media application affects its use.

\section{Research method}

The method of the study is a set of regulation, tools and some reliable and systematic ways to assess realities, to explore ambiguities, and to reach solutions. The method of the present study is based on the research objective; it is practical and, in terms of nature and methods, it belongs among causal studies. It tries to explore reasons or factors contributing to the occurrence of an event in social media. The statistical technique of structural equations is used, which is basically concerned with causal relationships between variables.

A questionnaire is designed with 27 pairs of questions for Telegram and Viber. Application quality questions are adopted from Chen et al. (2017), Zhou (2012), Wolfinbarger and Gilly (2003), Swaid and Wigand (2007) and Vijai (2018), and TAM-related questions are adopted from Shaikh et al. (2015) and Rahi et al. (2018) (see Appendix A). 


\section{Statistical population and sampling method}

The statistical population is social media users from the city of Neyshabur in Iran. Given the limitation of the sample of the study, Cochran's formula is used for sample selection. Based on Cochran's sample size formula, the adequate sample size is 384 people. We chose 500 people and the number of valid returned questionnaires was 401. Data were gathered using a field method, in which the questionnaire is a common method for collecting information. The questionnaire was completed by social media users from Neyshabur. The questionnaire was designed as indicated in Section 4 and used for data collection. Validity means the appropriateness of data and that the metric tool is able to measure a certain characteristic or feature. Several social media experts analysed the validity of the questionnaire and their corrective comments were considered.

Hence, the questionnaire used as the data collection tool has the required validity. In order to measure the reliability, an index is used called the reliability coefficient. The range of the reliability coefficient is between 0 and 1 . Zero reliability coefficients are indicative of lack of reliability and a reliability coefficient of one is equal to total reliability. The range of functionality of a measurement tool is for maintaining its consistency in time. In order to ensure clarity of the questions, to localize the scales, and to adapt to the statistical population, we performed primary investigations and determined the validity of the questionnaire. To do that, the questionnaire was distributed tentatively among 30 persons. The Cronbach's alpha coefficient was used in order to measure the validity of the questionnaire. Using the SPSS software, the Cronbach's alpha coefficient for the questionnaire was 0.79 .

\section{Data Analysis}

The structural equation modelling method is used for data analysis and testing the research hypotheses. It is a comprehensive statistical approach for testing hypotheses relative to relationships between observed and hidden variables. We used it on the effect of hidden variables. The path diagram is a graphic display of structural equations that is comprised of three major components of circles and arrows. This class of equations deals with assumed relationships between hidden variables in a model, through which standardized coefficients of regression (path coefficients) are calculated. Those variables defined in the model are independent variables in one equation and dependent variables in another equation, which results in a correlation and interconnectedness in an equation paradigm. Therefore, all equations should be taken into account at the same time. Figures 2 and 3 show the structural model of the present study in standardized coefficients and significant figure modes. The paradigm shows the overall relationship between hidden and observable variables in the same model. The path coefficients are depicted in Figure 2. The numbers on the arrows are indicative of path coefficients related to variables, which are computed using the Smart PLS software. The circles show the variables and the squares illustrate the questions related to these variables, namely related to system quality (SYSQ), information quality (INFQ), service quality (SERQ), personalization (PER), perceived usefulness (PU), perceived ease of use (PEOU), attitude to using the application (ATT), facilitating condition (FC), use of the social media application (USE), use of the application for news (USENEWS), intention to use the social media application (INT), and intention to use the application for news (INTNEWS).

The test statistic values for each coefficient are illustrated in Figure 3. Here, a $t$ value is observed for each parameter in the model and we can conclude that when the number of samples is more than 30 and the observed $t$ is more than 1.96 , the equation is significant with more than $95 \%$ of confidence. 


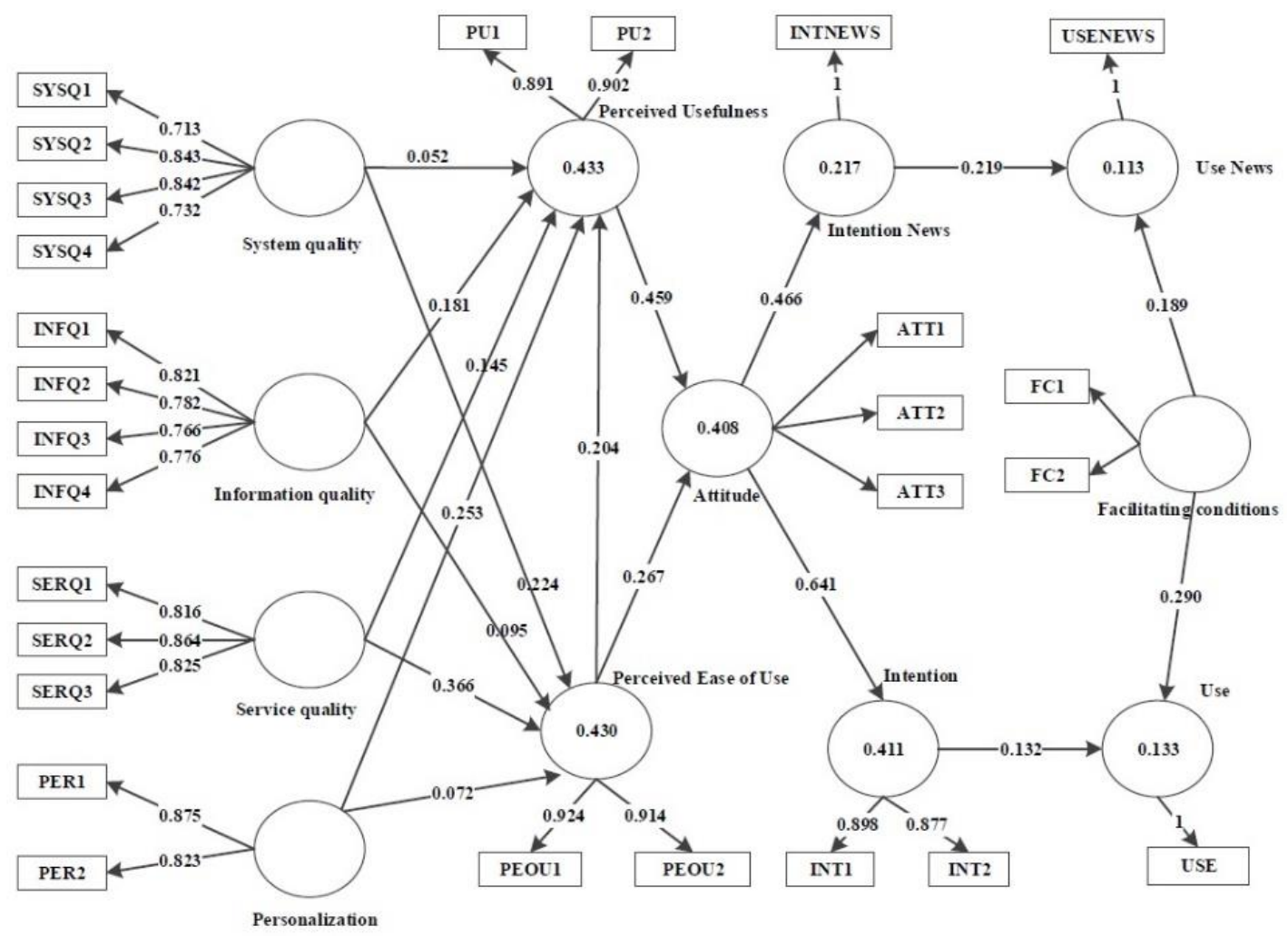

Figure 2. Path coefficients of proposed model.

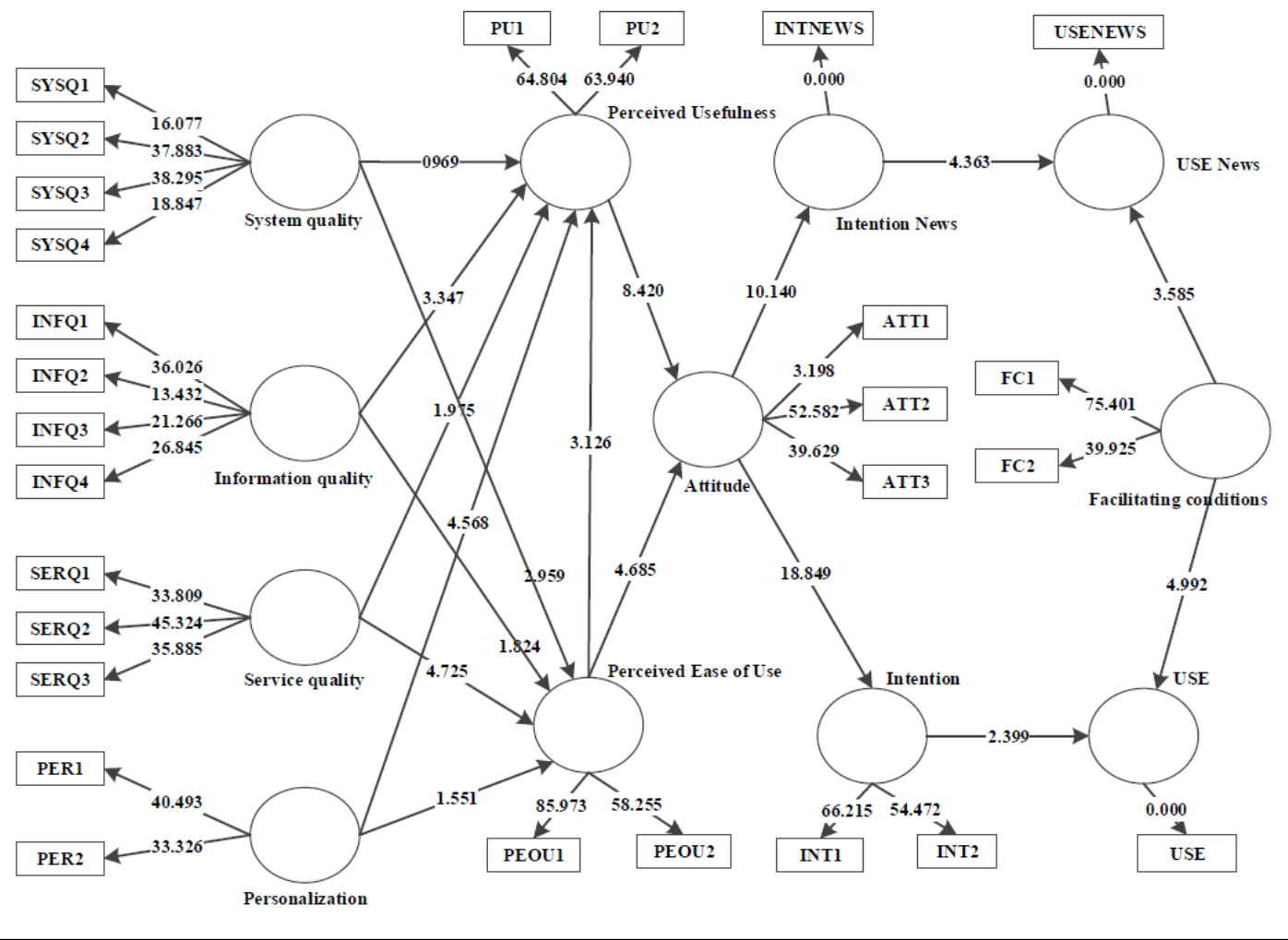

|Figure 3. T-value coefficients of proposed model.

We use tests of goodness of fit (see Table 1) to evaluate the model fitting including the goodness-of-fit index (GFI), the adjusted goodness-of-fit index (AGFI), the root mean square error of approximation 
(RMSEA), the standardized root mean square residual (SRMR) and minimum discrepancy per degree of freedom (CMIN/DF) (Moss et al., 2015).

Table 1. Values of fitting indexes and results of structural model fitting.

\begin{tabular}{|l|l|l|l|l|l|l|l|l|}
\hline Fitting index & IFI & NFI & NNFI & GFI & AGFI & RMSEA & SRMR & CMIN/DF \\
\hline Threshold & $>0.9$ & $>0.9$ & $>0.9$ & $>0.9$ & $>0.9$ & $<0.08$ & $<0.05$ & $<3$ \\
\hline Value & 0.93 & 0.92 & 0.94 & 0.88 & 0.95 & 0.041 & 0.02 & 1.22 \\
\hline
\end{tabular}

The output of the structural equations and the $t$ test indicates that the path existing among independent hidden variables and dependent hidden ones is significant. Table 2 depicts a summary of results obtained from hypothesis testing. Two of the common social media that are used in Iran are Telegram and Viber. Previously, people mostly used Viber, but now they use Telegram. For this reason, we considered these two social media applications in our survey. Initially, in order to recognize the use and to compare the research variables in Telegram and Viber, data normality should be analysed, for which the KolmogorovSmirnov test was used. The results revealed that the data for the two groups of Telegram and Viber were not normal, so the Mann-Whitney $U$ test was used for the comparison instead.

Table 2. Structural model results.

\begin{tabular}{|c|c|c|c|}
\hline Hypothesis & Standard path value & T value & $\begin{array}{c}\text { Hypothesis } \\
\text { supported }\end{array}$ \\
\hline H1 & 0.062 & 0.969 & No \\
\hline H2 & 0.181 & 3.347 & Yes \\
\hline H3 & 0.145 & 1.975 & Yes \\
\hline H4 & 0.253 & 4.568 & Yes \\
\hline H5 & 0.224 & 2.952 & Yes \\
\hline H6 & 0.095 & 1.824 & No \\
\hline H7 & 0.366 & 7.725 & Yes \\
\hline H8 & 0.072 & 1.551 & No \\
\hline H9 & 0.204 & 3.128 & Yes \\
\hline H10 & 0.459 & 8.420 & Yes \\
\hline H11 & 0.267 & 4.685 & Yes \\
\hline H12 & 0.468 & 10.140 & Yes \\
\hline H13 & 0.641 & 18.849 & Yes \\
\hline H14 & 0.188 & 3.685 & Yes \\
\hline H15 & 0.290 & 4.992 & Yes \\
\hline H16 & 0.132 & 4.363 & \\
\hline H17 & 0.219 & & \\
\hline
\end{tabular}

The Mann-Whitney $\mathrm{U}$ is a non-parametric test concerned with the difference between two independent groups of variables with ranked or sequential data. The level of significance of the test for all the variables under study is between 0 and 1, which is less than 0.05 error level. Hence, we can conclude that the null hypothesis of the Mann-Whitney $U$ test is rejected and its opposite hypothesis, namely the difference of average score of variables in two groups of Telegram and Viber is approved. In other words, the average score of all research variables is not the same in Telegram and Viber. The next step is to determine the direction of the mean difference using the ranked means. In fact, the ranked means determine which 
variable is more or less in which group (Telegram or Viber). The results of the ranked means are shown in Table 3 and the diagrams depicted in Figure 4 reveal that in all the variables under study, Telegram has a more appropriate condition than Viber.

Table 3. Difference of variables between Telegram and Viber using ranked means.

\begin{tabular}{|c|c|c|}
\hline Research variable & Group & Mean Rank \\
\hline \multirow{2}{*}{ Information quality } & Telegram & 530.22 \\
\hline & Viber & 272.78 \\
\hline \multirow{2}{*}{ System quality } & Telegram & 532.89 \\
\hline & Viber & 271.11 \\
\hline \multirow{2}{*}{ Service quality } & Telegram & 523.77 \\
\hline & Viber & 279.23 \\
\hline \multirow{2}{*}{ Personalization } & Telegram & 466.98 \\
\hline & Viber & 236.02 \\
\hline \multirow{2}{*}{ Perceived usefulness } & Telegram & 483.83 \\
\hline & Viber & 319.17 \\
\hline \multirow{2}{*}{ Perceived ease of use } & Telegram & 497.25 \\
\hline & Viber & 305.75 \\
\hline \multirow{2}{*}{ Facilitating conditions } & Telegram & 471.92 \\
\hline & Viber & 331.08 \\
\hline \multirow{2}{*}{ Attitude } & Telegram & 499.18 \\
\hline & Viber & 303.82 \\
\hline \multirow{2}{*}{ Use Intention } & Telegram & 497.34 \\
\hline & Viber & 305.66 \\
\hline \multirow{2}{*}{ Use } & Telegram & 563.77 \\
\hline & Viber & 239.23 \\
\hline \multirow{2}{*}{ Use Intention-news } & Telegram & 497.85 \\
\hline & Viber & 305.42 \\
\hline \multirow{2}{*}{ Use-news } & Telegram & 550.63 \\
\hline & Viber & 252.37 \\
\hline
\end{tabular}




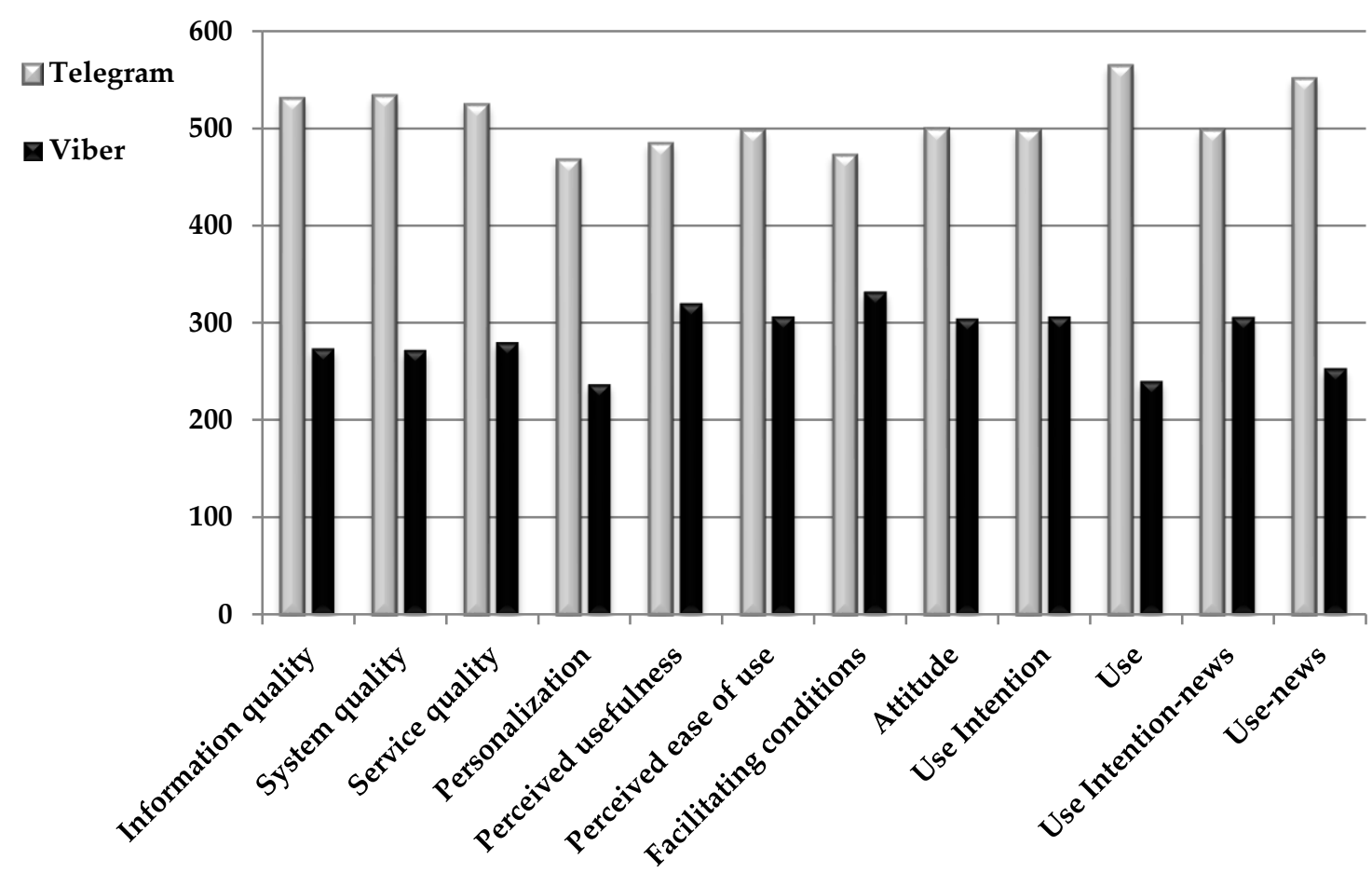

Figure 4. Difference between variables under study in Telegram and Viber using ranked mean.

\section{Discussion}

Regarding the effect of perceived ease of use on perceived usefulness and attitude, the results of previous studies have shown that perceived ease of use contributes to perceived usefulness and user attitude to the use of a technology. The results of the study of Hsu et al. (2014) are in line with this fact. Moreover, perceived usefulness has a positive effect on the attitude and intention to use. In Hussein et al. (2021) and Islami et al. (2021), perceived usefulness also has a positive impact on user attitude. In addition, the results revealed that facilitating conditions have a positive and significant impact on use of social media and use of social media for news, which is in line with the results of König and Grippenkoven (2020). Furthermore, the relationship between facilitating conditions and use of social media and use of social media for news means that meeting the required conditions and facilities for the use of information technology could affect the acceptance and use of the related technology. The results show that system quality has no relationship with perceived usefulness, similar to the work by Kim et al. (2019), which states that there is no significant relationship between system quality and perceived usefulness. However, there is a significant and positive association between system quality and perceived ease of use. Besides, service quality has a positive relationship with perceived usefulness and perceived ease of use, which is confirmed by Kim et al. (2019). Information quality has a positive and significant relationship with perceived usefulness and perceived ease of use, and the relationship between personalization and perceived usefulness is positive and significant, which is similar to the study of Almaiah et al. (2016).

Moreover, attitude with the respective $64 \%$ and $46 \%$ path coefficient values has the maximum of effect on the intention to use social media and to use social media for news. Different studies confirm our results for the effects of attitude on intention to use and use of a technology. For example, the study by Kasilingam (2020) shows that attitude plays an important and significant role in intentions to use online shopping. According to Alqasa et al. (2014), attitude is the main factor that influences students to use the services of banking systems. Attitude is affected by perceived usefulness (with a $45 \%$ path coefficient) and perceived ease of use (with a $26 \%$ path coefficient). Kuo and Yen (2009) state that perceived usefulness and ease of use have positive effects on attitude towards using 3G mobile phones. Weng et al. (2018) show that both 
perceived usefulness and ease of use have positive effects on attitude and intention to use multimedia among school teachers; their findings are in line with our results.

With a relatively high path coefficient equal to $25 \%$, personalization affects perceived usefulness. It is matched by Desai (2018), who shows that a high level of perceived personalization in a website enhances the perceived usefulness and perceived ease of use of the website, as well as Serrano-Malebrán and Arenas-Gaitán (2021), who show that personalization of advertising influences usefulness perceived by users. The results show that personalization has the maximum effect on perceived usefulness; thus, this fact should be considered during the design of software applications. The path coefficient of perceived ease of use towards perceived usefulness is $20 \%$. Many studies support the findings of our work, including Tubaishat (2017), who shows the positive path between perceived ease of use and perceived usefulness of electronic health records among nurses, as well as Al-Sharafi et al. (2017) for using online banking services. With path coefficients at $18 \%$, information quality is related to perceived usefulness. The results of our study are supported by the findings of Machdar (2019), who states that quality of information has a positive effect on perceived usefulness. Service quality also has a positive effect on perceived usefulness with path coefficients at $14 \%$. These results are according to Jang and Noh (2011), who show that service quality has a positive effect on the usefulness of Internet protocol television. Service quality has a positive and high effect on ease of use with a path coefficient equal to $36 \%$. The result is in line with the findings of Mustapha and Obid (2015) for a direct positive relationship between service quality and perceived ease of use. It has also been shown that system quality, with path coefficients of $22 \%$, has significant influence on perceived ease of use; this is confirmed by Gupta et al. (2021).

\section{Conclusion}

Today there is a fierce competition among social media designers. Thus, being familiar with the factors that contribute to the use of social media is important, which has been investigated in this study. Based on our results, attitude has the maximum impact on the intention to use social media and the intention to use social media for news. Our results show that perceived usefulness has more impact (with a path coefficient of $45 \%$ ) on the attitude than perceived ease of use (path coefficient of $26 \%$ ). The obtained results indicate that four factors of system quality, information quality, service quality and personalization of applications could affect the perceived usefulness. System quality and service quality have an impact on the ease of use of applications, while information quality has no effect on the perceived ease of use.

Moreover, personalization has the maximum of impact on the perceived usefulness and service quality contributes greatly to the perceived ease of use. In addition, facilitating conditions may affect the use of social media and use of social media for news. Furthermore, our results show that the factors that affect using of social media applications and using them for news are better in Telegram than in Viber, and this can be a good reason for more users using of Telegram than Viber in Iran. Therefore, this research recommends social media application designers to consider paying more attention to service quality and personalization to increase popularity and use and to provide the required conditions and facilities for the use of social media.

\section{Additional Information and Declarations}

Conflict of Interests: The authors declare no conflict of interest.

Author Contributions: D.F.: Data collection, Writing - Original draft preparation, Methodology. A.M: Supervision, Conceptualization, Methodology, Writing - Reviewing and Editing.

Data Availability: The data that support the findings of this study are available from the corresponding author. 


\section{Appendix A}

Main questionnaire items for Telegram in English (for Viber change Telegram to Viber).

Information quality

1. Telegram provides me with information relevant to my needs (Chen, 2017; Zhou, 2012).

2. Telegram provides me with sufficient information (Chen, 2017; Zhou, 2012).

3. Telegram provides me with accurate information (Chen, 2017; Zhou, 2012).

4. Telegram provides me with up-to-date information (Chen, 2017; Zhou, 2012).

System quality

1. Telegram quickly loads all the text and graphics (Chen, 2017; Zhou, 2012).

2. Telegram is easy to use (Chen, 2017; Zhou, 2012).

3. Telegram is easy to navigate (Chen, 2017; Zhou, 2012).

4. Telegram is visually attractive (Chen, 2017; Zhou, 2012).

Service quality

1. Telegram provides on-time services (Chen, 2017; Zhou, 2012).

2. Telegram provides prompt responses (Chen, 2017; Zhou, 2012).

3. Telegram provides professional (Chen, 2017; Zhou, 2012).

Personalization

1. Telegram gives me personal attention (Wolfinbarger and Gilly, 2003; Swaid and Wigand, 2007).

2. Telegram has features that are personalized for me (Wolfinbarger and Gilly, 2003; Swaid and Wigand, 2007).

Perceived usefulness

1. I think Telegram is useful (Shaikh et al., 2015; Rahi et al., 2018).

2. I think that using Telegram would make it easier for me to carry out tasks such as exchanging information with others (Shaikh et al., 2015).

Perceived ease of use

1. Learning to operate Telegram would be easy for me (Shaikh et al., 2015; Rahi et al., 2018).

2. I would find Telegram easy to use (Shaikh et al., 2015; Rahi et al., 2018).

Facilitating conditions

1. I have the necessary resources to use Telegram, including a smartphone and internet connection (Rahi et al., 2018).

2. I have the necessary knowledge to use Telegram (Rahi et al., 2018).

Attitude

1. Using Telegram would be a good idea (Shaikh et al., 2015).

2. I like the idea of using Telegram (Shaikh et al., 2015).

3. Using Telegram would be pleasant (Shaikh et al., 2015).

Intention to use

1. I would use Telegram (Shaikh et al., 2015).

2. I can see myself using Telegram (Shaikh et al., 2015). 
Intention to use for news

1. I would use Telegram for news (Shaikh et al., 2015).

Use

1. I am using Telegram.

Use for news

1. I am using Telegram for news.

\section{References}

Akbari, A., \& Gabdulhakov, R. (2019). Platform Surveillance and Resistance in Iran and Russia: The Case of Telegram. Surveillance \& Society, 17(1/2), 223-231. https://doi.org/10.24908/ss.v17i1/2.12928

Aliman, N. K., \& Mohamad, W. N. (2016). Linking Service Quality, Patients' Satisfaction and Behavioral Intentions: An Investigation on Private Healthcare in Malaysia. Procedia - Social and Behavioral Sciences, 224, 141-148. https://doi.org/10.1016/j.sbspro.2016.05.419

Almaiah, M. A., Jalil, M. A., \& Man, M. (2016). Extending the TAM to examine the effects of quality features on mobile learning acceptance. Journal of Computers in Education, 3(4), 453-485. https://doi.org/10.1007/s40692-016-0074-1

Al-Mamary, Y.H., Shamsuddin, A., \& Aziati, N. (2014). The Relationship between System Quality, Information Quality, and Organizational Performance. International Journal of Knowledge and Research in Management and E-Commerce, 4, 710.

Alqasa, K.M., Mohd Isa, F., Othman, S.N., \& Zolait, A.H.S. (2014). The impact of students' attitude and subjective norm on the behavioural intention to use services of banking system. International journal of business information systems, 15(1), $105-122$.

Al-Sharafi, M.A., Arshah, R.A., Herzallah, F.A., \& Alajmi, Q. (2017). The effect of perceived ease of use and usefulness on customers intention to use online banking services: the mediating role of perceived trust. International Journal of Innovative Computing, 7(1), 9-14.

Chaeikar, S. S., Yazdanpanah, S., \& Chaeikar, N. S. (2021). Secure SMS transmission based on social network messages. International Journal of Internet Technology and Secured Transactions, 11(2), 176. https://doi.org/10.1504/ijitst.2021.113519

Chan, L.-K., \& Lau, P.-Y. (2018). Investigating the Impact of System Quality on Service-Oriented Business Intelligence Architecture. SAGE Open, 8(4), 215824401880552. https://doi.org/10.1177/2158244018805527

Chen, X., Huang, Q., \& Davison, R. M. (2017). The role of website quality and social capital in building buyers' loyalty. International Journal of Information Management, 37(1), 1563-1574. https://doi.org/10.1016/j.ijinfomgt.2016.07.005

Desai, D. (2018). An Empirical Study of Website Personalization Effect on Users Intention to Revisit E-commerce Website Through Cognitive and Hedonic Experience. In Data Management, Analytics and Innovation (pp. 3-19). Springer Singapore. https://doi.org/10.1007/978-981-13-1274-8 1

Duy, P. N. N., \& Hoang, T. M. (2017). Factors affecting customer satisfaction and customer loyalty the case of binh duong ceramic product. In Proceedings of NIDA International Business Conference 2017 - Innovative Management (pp. 380405). NIDA.

Faramarzi, S., Tabrizi, H. H., \& Chalak, A. (2019). Telegram: An instant messaging application to assist distance language learning. Teaching English with Technology, 19(1), 132-147.

Gilavand, A., Shooriabi, M., \& Mansoori, B. (2017). Investigating the use of social networking sites for dental education by students: A regional survey. Annals of Dental Specialty, 5(3), 93-96.

Grange, C., \& Barki, H. (2020). The Nature and Role of User Beliefs Regarding a Website's Design Quality. Journal of Organizational and End User Computing, 32(1), 75-96. https://doi.org/10.4018/joeuc.2020010105

Gupta, P., Prashar, S., Vijay, T. S., \& Parsad, C. (2021). Examining the influence of antecedents of continuous intention to use an informational app: the role of perceived usefulness and perceived ease of use. International Journal of Business Information Systems, 36(2), 270-287.

Halawi, L. A., McCarthy, R. V., \& Aronson, J. E. (2008). An empirical investigation of knowledge management systems' success. Journal of Computer Information System, 48(2), 121-135.

Hanks, L., Line, N., \& Kim, W. G. W. (2017). The impact of the social servicescape, density, and restaurant type on perceptions of interpersonal service quality. International Journal of Hospitality Management, 61, 35-44. https://doi.org/10.1016/j.ijhm.2016.10.009

Hashemi, A., \& Zare Chahooki, M. A. (2019). Telegram group quality measurement by user behavior analysis. Social Network Analysis and Mining, 9(1). https://doi.org/10.1007/s13278-019-0575-9

Hsu, C.-L., Yu, C.-C., \& Wu, C.-C. (2013). Exploring the continuance intention of social networking websites: an empirical research. Information Systems and E-Business Management, 12(2), 139-163. https://doi.org/10.1007/s10257-013-0214-3 
Hussein, R. S., Mohamed, H., \& Kais, A. (2021). Antecedents of level of social media use: exploring the mediating effect of usefulness, attitude and satisfaction. Journal of Marketing Communications, 1-22. https://doi.org/10.1080/13527266.2021.1936125

Islami, M. M., Asdar, M., \& Baumassepe, A. N. (2021). Analysis of Perceived Usefulness and Perceived Ease of Use to the Actual System Usage through Attitude Using Online Guidance Application. Hasanuddin Journal of Business Strategy, 3(1), 52-64. https://doi.org/10.26487/hjbs.v3i1.410

Kang, J.-W., \& Namkung, Y. (2019). The information quality and source credibility matter in customers' evaluation toward food O2O commerce. International Journal of Hospitality Management, 78, 189-198. https://doi.org/10.1016/j.ijhm.2018.10.011

Kang, J., Tang, L., \& Fiore, A. M. (2014). Enhancing consumer-brand relationships on restaurant Facebook fan pages: Maximizing consumer benefits and increasing active participation. International Journal of Hospitality Management, 36, 145-155. https://doi.org/10.1016/j.ijhm.2013.08.015

Karimpour, D., Chahooki, M. A. Z., \& Hashemi, A. (2021). Telegram group recommendation based on users' migration. In 2021 26th International Computer Conference, Computer Society of Iran (CSICC) (pp. 1-6). IEEE. https://doi.org/10.1109/CSICC52343.2021.9420581

Kasilingam, D. L. (2020). Understanding the attitude and intention to use smartphone chatbots for shopping. Technology in Society, 62, 101280. https://doi.org/10.1016/j.techsoc.2020.101280

Khiabany, G. (2018). Citizenship and Cyber Politics in Iran. In Digital Middle East (pp. 217-238). Oxford University Press.

Kim, S., Lee, S., \& Lee, K. (2019). An Effect of Information System Quality of BRIS on Perceived Usefulness and User's Continuous Use Intention. Agribusiness and Information Management, 11(2), 16-24. https://doi.org/10.14771/aim.11.2.2

König, A., \& Grippenkoven, J. (2020). The Actual Demand Behind Demand-Responsive Transport: Assessing Behavioral Intention to Use DRT Systems in two Rural Areas in Germany. Case Studies on Transport Policy, 8(3), 954-962. https://doi.org/10.1016/i.cstp.2020.04.011

Kuo, Y.-F., \& Yen, S.-N. (2009). Towards an understanding of the behavioral intention to use 3G mobile value-added services. Computers in Human Behavior, 25(1), 103-110. https://doi.org/10.1016/i.chb.2008.07.007

Li, Y., \& Shang, H. (2020). Service quality, perceived value, and citizens' continuous-use intention regarding e-government: Empirical evidence from China. Information \& Management, 57(3), 103197. https://doi.org/10.1016/j.im.2019.103197

Machdar, N. M. (2019). The effect of information quality on perceived usefulness and perceived ease of use. Business and Entrepreneurial Review, 15(2), 131. https://doi.org/10.25105/ber.v15i2.4630

Meesala, A., \& Paul, J. (2018). Service quality, consumer satisfaction and loyalty in hospitals: Thinking for the future. Journal of Retailing and Consumer Services, 40, 261-269. https://doi.org/10.1016/j.jretconser.2016.10.011

Mehdipour, S., Jannati, N., Negarestani, M., Amirzadeh, S., Keshvardoost, S., Zolala, F., ... \& Fatehi, F. (2021). Health Pandemic and Social Media: A Content Analysis of COVID-Related Posts on a Telegram Channel With More Than One Million Subscribers. In Navigating Healthcare Through Challenging Times (pp. 122-129). IOS Press.

Mensah, I. K. (2020). Perceived Usefulness and Ease of Use of Mobile Government Services. International Journal of Technology Diffusion, 11(1), 1-16. https://doi.org/10.4018/ijtd.2020010101

Moore, G. C., \& Benbasat, I. (1991). Development of an instrument to measure the perception ofadopting an information technology innovation. Information System Research, 2, 192-222.

Moss, T. P., Lawson, V., \& White, P. (2015). Identification of the underlying factor structure of the Derriford Appearance Scale 24. PeerJ, 3, e1070. https://doi.org/10.7717/peerj.1070

Mustapha, B., \& Obid, S. N. Bt. S. (2015). Tax Service Quality: The Mediating Effect of Perceived Ease of Use of the Online Tax System. Procedia - Social and Behavioral Sciences, 172, 2-9. https://doi.org/10.1016/..sbspro.2015.01.328

Narmenji, S. M., Nowkarizi, M., Riahinia, N., \& Zerehsaz, M. (2020). Investigating the Behavior of Sharing Information of Students in the Virtual Social Networks: Instagram, Telegram and WhatsApp. Sciences and Techniques of Information Management, 6(4), 49-78.

Nurbani, K., \& Meiyanti, F. (2019). The Impact of System Quality and Information Quality on User Satisfaction and User Performance. Jurnal Akuntansi, Manajemen dan Ekonomi, 21(2), 1-9.

Pang, S., Bao, P., Hao, W., Kim, J., \& Gu, W. (2020). Knowledge Sharing Platforms: An Empirical Study of the Factors Affecting Continued Use Intention. Sustainability, 12(6), 2341. https://doi.org/10.3390/su12062341

Rahi, S., Abd. Ghani, M., Alnaser, F. M., \& Ngah, A. H. (2018). Investigating the role of unified theory of acceptance and use of technology (UTAUT) in internet banking adoption context. Management Science Letters, 173-186. https://doi.org/10.5267/j.msl.2018.1.001

Sarafraz, M. R., Chavoshi, H., \& Alinaghi, M. (2019). Social Networks and Students: Educational Performance, Psychological Well-Being, and Mental Health. International Journal of School Health, 6(3), 1-6. https://doi.org/10.5812/intjsh.82609

Scherer, R., Siddiq, F., \& Tondeur, J. (2019). The technology acceptance model (TAM): A meta-analytic structural equation modeling approach to explaining teachers' adoption of digital technology in education. Computers \& Education, 128, 1335. https://doi.org/10.1016/j.compedu.2018.09.009

Schillinger, F., \& Schindelhauer, C. (2020). Recovering Private User Storages in Online Social medias. Journal of Internet Technology and Secured Transactions, 8, 687-698. 
Serrano-Malebrán, J., \& Arenas-Gaitán, J. (2021). When does personalization work on social media? a posteriori segmentation of consumers. Multimedia Tools and Applications, 80(30), 36509-36528. https://doi.org/10.1007/s11042$\underline{021-11303-2}$

Shaikh, A.A., Glavee-Geo, R., \& Karjaluoto, H. (2015). An Empirical Investigation of Mobile Banking Services Adoption in Pakistan. World Academy of Science, Engineering and Technology, International Journal of Social, Behavioral, Educational, Economic, Business and Industrial Engineering, 9, 3797-3805.

Swaid, S. I., \& Wigand, R. T. (2007). Key dimensions of e-commerce service quality and its relationships to satisfaction and loyalty. In BLED 2007 Proceedings, (no. 29). AIS. http://aisel.aisnet.org/bled2007/29

Wolfinbarger, M., \& Gilly, M. C. (2003). eTailQ: dimensionalizing, measuring and predicting etail quality. Journal of Retailing, 79(3), 183-198. https://doi.org/10.1016/s0022-4359(03)00034-4

Shayegan, M. J., \& Valizadeh, M. (2020). A Recommender System based on the analysis of personality traits in Telegram social network. https://arxiv.org/abs/2010.00643

Tubaishat, A. (2017). Perceived usefulness and perceived ease of use of electronic health records among nurses: Application of Technology Acceptance Model. Informatics for Health and Social Care, 43(4), 379-389. https://doi.org/10.1080/17538157.2017.1363761

Ullah, A., Bin Baharun, R., Yasir, M., \& MD Nor, K. (2020). Enterprise Resource Planning Systems and User Performance in Higher Education Institutions of Pakistan. Journal of Applied Economics and Business Studies, 4(2), 119-140. https://doi.org/10.34260/jaebs.426

Vijai, J. P. (2018). Examining the relationship between system quality, knowledge quality and user satisfaction in the success of knowledge management system: an empirical study. International Journal of Knowledge Management Studies, 9(3), 203221. https://doi.org/10.1504/ijkms.2018.10015435

Weng, F., Yang, R.-J., Ho, H.-J., \& Su, H.-M. (2018). A TAM-Based Study of the Attitude towards Use Intention of Multimedia among School Teachers. Applied System Innovation, 1(3), 36. https://doi.org/10.3390/asi1030036

Yalcintas, A., \& Alizadeh, N. (2020). Digital protectionism and national planning in the age of the internet: the case of Iran. Journal of Institutional Economics, 16(4), 519-536. https://doi.org/10.1017/s1744137420000077

Yuan, X., Chu, K., \& Cai, S. (2018). When Is Information Quality More Important?: The Moderating Effects of Perceived Market Orientation and Shopping Value. Journal of Global Information Management, 26(2), 204-232.

Zhou, T. (2013). An empirical examination of continuance intention of mobile payment services. Decision Support Systems, 54(2), 1085-1091. https://doi.org/10.1016/j.dss.2012.10.034

Editorial record: The article has been peer-reviewed. First submission received on 2 August 2021. Revisions received on 28 September 2021, and 18 November 2021. Accepted for publication on 19 November 2021. The editor in charge of coordinating the peer-review of this manuscript and approving it for publication was Zdenek Smutny (D).

Acta Informatica Pragensia is published by Prague University of Economics and Business, Czech Republic.

ISSN: $1805-4951$ 